\title{
Urodimento
}

REVISTA DE ESTUDOS EM ARTES CÊNICAS

E-ISSN 2358.6958

\section{Efeitos de ausência: A tela contra a cena}

\author{
Didier Plassard
}

Tradução: Paulo Balardim

Para citar este artigo:

PLASSARD, Didier. Efeitos de ausência: A tela contra a cena. Trad. Paulo Balardim. Urdimento - Revista de Estudos em Artes Cênicas, Florianópolis, v. 2, n. 41, set. 2021.

dof DOI: http:/dx.doi.org/10.5965/1414573102412021e0701 


\begin{abstract}
Resumo
O artigo lança um olhar sobre a integração da imagem de vídeo na encenação contemporânea, discutindo a questão da complexidade que isso impõe aos modos de presença do intérprete, ao modo como se cruzam os espaçostempo ficcionais e ao desenvolvimento de níveis narrativos autônomos. Partindo da hipótese de que a integração em doses muito altas da imagem eletrônica na representação teatral tende, com diferentes encenadores, a ser acompanhada de uma rarefação, de uma desestruturação e até mesmo uma quase desaparição da ação cênica, o autor propõe examinar "efeitos de ausência", com base na observação de duas produções alemãs e uma italiana, realizadas entre 2002 e 2004: Der Meister und Margarita, encenado por Frank Castorf a partir do romance de Bulgakov4; Pablo in der Plusfiliale, espetáculo concebido e realizado por René Pollesch5; e Twin rooms, uma criação da companhia Motus.
\end{abstract}

Palavras-chave: Cena aumentada. Efeitos de ausência. Encenação contemporânea. Teatro. Vídeo.

${ }^{1}$ Artigo originalmente publicado in: Josette Féral et Edwige Perrot (dir.). Le réel à l'épreuve des technologies, les arts de la scène et les arts médiatiques. Rennes: Presses Universitaires de Rennes, 2013, p. 43-60. (Tradução inédita realizada em março de 2020, para fins didáticos, autorizada pelo autor).

2 Doutor em Estudos Teatrais (Université Paris 3). Professor na Université Paul-Valéry - Montpellier III. Pesquisador do projeto europeu PuppetPlays (ERC Advanced Grant 835193, 2019-2024). Seus trabalhos focam no teatro moderno e contemporâneo e nas relações do teatro com as outras artes e com as novas tecnologias. E-mail: didier.plassard@univ-montp3.fr $\quad$ (iD) https://orcid.org/0000-0002-2533-9460

${ }^{3}$ Doutor em Teatro (UDESC). Professor Associado do Departamento de Artes Cênicas e do Programa de PósGraduação em Teatro, Centro de Artes (CEART), Universidade do Estado de Santa Catarina (UDESC). E-mail : paulobalardim@gmail.com

9ttp://lattes.cnpq.br/9137483053075236

https://orcid.org/0000-0002-2586-2630

${ }^{4}$ Der Meister und Margarita, encenado por Frank Castorf, baseado no romance de Mikhail Bulgakov, estreou em 14 de junho de 2002 em Viena, como parte do Wiener Festwochen. Retomado em 9 de novembro de 2002 no Volksbühne, em Berlim.

5 Pablo in der Plusfiliale, espetáculo de René Pollesch, estreou em 26 de maio de 2004 na Volksbühne em Berlim. 
Effects of absence: the screen against the scene

\begin{abstract}
The article takes a look at the integration of the video image in contemporary staging, discussing the issue of complexity that this imposes on the modes of presence of the interpreter, the way in which fictional spaces-time intersect and the development of autonomous narrative levels. Starting from the hypothesis that the integration in very high doses of the electronic image in the theatrical representation tends, with different stage directors, to be accompanied by a rarefaction, a disruption and even a near disappearance of the scenic action, the author proposes to examine "effects of absencelO", based on the observation of two German and one Italian productions, carried out between 2002 and 2004: Der Meister und Margarita, staged by Frank Castorf from Bulgakov's novel; Pablo in der Plusfiliale, a show designed and performed by René Pollesch; and Twin rooms, created by the company Motus.
\end{abstract}

Keywords: Absence effects. Augmented scene. Contemporary staging. Theater. Video.

\title{
Efectos de ausencia: a pantalla contra la escena
}

\section{Resumen}

El artículo analiza la integración de la imagen de video en la puesta en escena contemporánea, discutiendo la cuestión de la complejidad que esto impone a los modos de presencia del intérprete, la forma en que se cruzan los espacios-tiempo ficcionales y el desarrollo de niveles narrativos autónomos. Partiendo de la hipótesis de que la integración en altísimas dosis de la imagen electrónica en la representación teatral tiende, con diferentes directores de escena, a ir acompañada de una rarefacción, una disrupción e incluso una casi desaparición de la acción escénica, el autor propone examinar "efectos de ausencia". Para ello, se basa en la observación de dos producciones alemanas y una italiana, realizadas entre 2002 y 2004: Der Meister und Margarita, puesta en escena por Frank Castorf de la novela de Bulgakov; Pablo in der Plusfiliale, espectáculo diseñado e interpretado por René Pollesch; y Twin rooms, creadas por la compañía Motus.

Palabras clave: Efectos de ausencia. Escena aumentada. Escenario contemporáneo. Teatro. Vídeo. 
Quando a fotografia elétrica, em séries, será introduzida no palco, [...] a projeção poderá se dizer onipotente e poucas coisas lhe serão recusadas.

(Adolphe Appia) $^{6}$

\section{Efeitos de ausência ou cena aumentada?}

A análise mais comum, ao considerar a integração da imagem de vídeo na encenação contemporânea, baseia-se na premissa de que a paleta expressiva do teatro seria cada vez mais ampliada: telas e monitores permitiriam aumentar a eficiência da representação teatral, dando origem, segundo alguns pesquisadores, a uma forma de "cena aumentada", no sentido em que falamos de "realidade aumentada" para designar a hibridação do real e do virtual. A complexificação dos modos de presença do intérprete, o cruzamento dos espaços-tempo ficcionais ou o desenvolvimento de níveis narrativos autônomos, resultantes da introdução dessas imagens na cena, simplesmente enriqueceriam os meios cenográficos e dramatúrgicos já testados, sem pôr em causa seus modos comuns de funcionamento.

Este postulado de um acréscimo das linguagens da imagem e da cena, que já era o das vanguardas históricas quando, desde $1916^{8}$, eles imaginavam associar projeção cinematográfica e representação teatral, hoje merece ser reexaminado. Desde meados dos anos 1990, de fato, surgiram dispositivos cênicos que, privilegiando telas muito grandes, a ausência duradoura de atores no palco ou o caráter intrusivo do equipamento técnico, inauguram uma nova direção de

${ }^{6}$ Adolphe Appia, Notes de mise en scène für Den Ring des Nibelungen (1891-1892), CEuvres complètes, vol. 1, L'Age d'homme, Lausanne, 1983, p. 114.

Analogia proposta em particular por Antonio Pizzo (Universidade de Turim), durante o dia de estudo Faire écran: le théâtre et son ailleurs selon Giorgio Barberio Corsetti, Universidade de Lille III, 20 de janeiro de 2009. Estritamente falando, no entanto, a denominação de "cena aumentada" deve ser aplicada exclusivamente aos dispositivos teatrais que envolvam efeitos de realidade virtual.

${ }^{8}$ Ver Pierre Albert-Birot, À propos d'un théâtre nunique, SIC, $\mathrm{n}{ }^{\circ}$ 8-9-10, agosto-outubro de 1916, reed. JeanMichel Place, Paris, 1980, p. [64]. 
trabalho na já longa história das relações entre a cena e a imagem projetada: a variação dos registros de presença ${ }^{9}$, explorados por Jacques Poliéri, Josef Svoboda e a cena experimental americana na década de 1960, sistematizados por tantos encenadores e coreógrafos nas décadas seguintes, neste caso deixa espaço para o que eu seria tentado chamar de "efeitos de ausência".

Em 1994, o monólogo Slight return ${ }^{10}$, do autor e encenador nova-iorquino John Jesurun, trancou o intérprete, durante toda a duração da representação, dentro de um cubo de madeira com 2 metros de largura colocado no palco. Apenas uma fileira de 5 monitores de vídeo, suspensos em frente a este cubo cego, permitiu que os espectadores seguissem o que estava acontecendo lá dentro e indiretamente vissem o intérprete. No mesmo ano, The merchant of Venice $^{11}$, de Shakespeare, na produção de Peter Sellars, acompanhou quase toda a ação cênica por meio da captura em vídeo, filmada ao vivo na cena e depois retransmitida em monitores suspensos acima das fileiras do público. Sem localização na sala que the permitisse olhar simultaneamente para o palco e o monitor mais próximo, o espectador foi levado a direcionar os olhos alternadamente para um ou outro, ciente do fato de que cada uma de suas escolhas the forçava a desistir de informações vindas da cena (real ou eletrônica) que ele parava de olhar por um momento e, até certo ponto, de ver. Além disso, a presença insistente de microfones e câmeras no palco (geralmente usadas pelos atores), como monitores e computadores, criou em torno dos intérpretes um "arsenal eletrônico"12 que modificou profundamente as relações interpessoais, interferindo repetidamente em seu jogo.

Esses exemplos, escolhidos entre outros, constituem as premissas de uma evolução que, em poucos anos, se tornou mais acentuada. Longe de contribuir para configurar uma "cena aumentada", agregando aos mais antigos prestígios do

\footnotetext{
${ }^{9}$ Conceito desenvolvido pela equipe Théâtre et cinéma do Laboratório de Pesquisa em Artes Cênicas do CNRS; ver Béatrice Picon-vallin, Hybridation spatiale, registres de présence, In: Picon-Vallin (dir.), Les Écrans sur la scène, L'Age d'homme, Lausanne, 1998, p. 28-29.

${ }^{10}$ Fotos e outras informações disponíveis em: https://sites.google.com/site/johnjesurun/16slightreturn(1994) (N.T.)

${ }^{11}$ Trechos do espetáculo podem ser vistos em: https://www.youtube.com/watch?v=nytLWFl961M (N.T.)

${ }^{12}$ Frédéric Maurin, Usages et usures de l'image - Spéculations sur Le Marchand de Venise vu par Peter Sellars, in: Béatrice Picon-Vallin (dir.), Les Écrans sur la scène, L'Age d'homme, Lausanne, 1998, p. 96.
} 
teatro o eco das tecnologias mais recentes, a integração em doses muito altas da imagem eletrônica na representação teatral tende, em diferentes encenadores, a ser acompanhada de uma rarefação, de uma desestruturação e até mesmo uma quase desaparição da ação cênica. São esses "efeitos de ausência" que proponho examinar aqui, baseados em duas produções alemãs e uma italiana, realizadas entre 2002 e 2004: Der Meister und Margarita, encenado por Frank Castorf a partir do romance de Bulgakov³; Pablo in der Plusfiliale, espetáculo concebido e realizado por René Pollesch"14; e Twin rooms, uma criação da companhia Motus ${ }^{15}$. Antes, porém, apresentarei rapidamente a estrutura interpretativa geral em que se inserirão essas análises.

\section{Revolução digital e espetáculo vivo}

Entre as muitas mutações nas sociedades contemporâneas, há duas que têm consequências importantes para as artes cênicas, levando a uma redefinição dos protocolos e questões de suas manifestações. A primeira é o que ficou conhecido como "revolução digital", e se estende em áreas cada vez maiores da vida social e privada, tecnologias da informática e redes. Essas, sem estarmos sempre conscientes disso, transformam profundamente nossos sistemas de representações, no sentido mais literal do termo: ou seja, as estratégias pelas quais construímos uma série de estados intermediários (portanto transições, negociações etc.) entre presença e ausência, o "fort" e o "da" da criança observados por sigmund Freud $^{16}$. As novas tecnologias da informação e comunicação - é uma banalidade notar isso - nos levam cada vez mais a lidar com esses estados intermediários, essas ausências quase presentes, essas presenças

${ }^{13}$ Der Meister und Margarita, encenado por Frank Castorf, baseado no romance de Mikhail Bulgakov, estreou em 14 de junho de 2002 em Viena, como parte do Wiener Festwochen. Retomado em 9 de novembro de 2002 no Volksbühne, em Berlim.

${ }^{14}$ Pablo in der Plusfiliale, espetáculo de René Pollesch, estreou em 26 de maio de 2004 na Volksbühne em Berlim.

15 Twin rooms, espetáculo projetado e produzido por Enrico Casagrande e Daniela Nicolo, companhia Motus, estreou em 9 de fevereiro de 2002 em Veneza, como parte da Bienal. Trecho pode ser visto em: https://vimeo.com/9015857.

${ }^{16}$ Ver Sigmund Freud, Au-delà du principe de plaisir, Payot, Paris, 1968, p. 52. 
parcialmente ausentes, cujo alcance não para de expandir. Daí a hipótese, formulada em particular por Hans-Thies Lehmann, segundo a qual as artes do espetáculo, envolvendo presença e não a representação ${ }^{17}$, assumiriam hoje uma função compensatória em vista do crescente espaço ocupado por simulacros técnicos em nossas vidas: o teatro e a dança permitiriam reencontrar a espessura e a semente da presença corporal, carregando-a com uma aura (no sentido de Walter Benjamin) da qual nenhuma imagem gravada, mesmo que interativa, não pode se revestir. A presença física constituiria, assim, o novo horizonte de expectativa das artes cênicas, a performatividade, sua nova gramática.

A segunda mutação é o fracionamento das coletividades preexistentes, das solidariedades familiares, locais ou profissionais, e o crescente isolamento do indivíduo em uma massa humana que, fisicamente presente, permanece estranha a ele. Para usar as análises de David Le Breton¹8, o sujeito ocidental contemporâneo é construído a partir de uma série de cortes simbólicos em relação ao mundo, aos que o rodeiam, mas também a sua própria existência corporal. A percepção em comum de uma mesma obra, em um mesmo tempo e num mesmo lugar, assume, portanto, um valor particular. Sem ir tão longe a ponto de pensar, como Denis Guénoun, que a reunião do público em uma sala confere, por si só, uma dimensão política ao teatro ${ }^{19}$, podemos considerar que o compartilhamento de significado e emoção, o qual Schiller já tinha como uma das chaves da utilidade moral do teatro ${ }^{20}$, permite a construção de um sentimento de comunidade tornado ainda

17 Hans-Thies Lehmann, Postdramatisches Theater, Verlag der Autoren, Frankfurt / Main, 1999, p. 146. Refirome aqui à edição alemã, e não à tradução francesa ( L'Arche, 2002), que apresenta alguns erros e, sobretudo, cortada em um terço em comparação com o texto original.

18 Ver David Le Breton, Anthropologie du corps et modernité, PUF, Paris, 1990.

${ }^{19}$ Ver Denis Guénoun, L'Exhibition des mots et autres idées du théâtre et de la philosophie, Circé, Belfort, 1998, p. 10; e, para uma breve discussão desta tese que, do meu ponto de vista, confunde a instituição de um espaço religioso com a de um espaço político: Didier Plassard, Théâtre et politique - L'écriture de la violence dans Fin de partie et En attendant Godot, Études théâtrales, $n^{\circ}$ 20, Centre d'Études Théâtrales, Louvain, março de 2001, p. 79.

20 "[...] quel triomphe pour toi, ô Nature, [...] de voir des hommes de toutes les classes, de tous les pays, [...] devenus frères par la toute-puissance de la sympathie, [...] se fondre de nouveau en une seule famille [...]. Chaque spectateur partage le ravissement de tous, et reflèté par mille yeux, ce ravissement revient avec plus de force et d'éclat dans son cœur, qui n'est alors rempli que d'un seul sentiment, celui d'être homme" (Friedrich von Schiller, "Le théâtre considéré comme institution morale", Mélanges philosophiques, esthétiques et littéraires, trad. por F. Wege, Paris, Hachette, 1840, p. 385-386). (N.A.) / "[...] que triunfo para você, ó Natureza, [...] ver homens de todas as classes, de todos os países, [...] tornarem-se irmãos pela onipotência da simpatia, [...] fundirem-se novamente em uma família [...]. Cada espectador compartilha o 
mais precioso hoje. Compreender e sentir, de maneira efêmera, o que os estranhos sentados ao seu redor entendem e sentem, torna-se, assim, um elemento fundador da experiência do espectador de teatro, diferentemente do cinema cuja atenção, constantemente revivida pela edição, foca quase exclusivamente na tela.

Resulta desses diferentes fatores que o duplo fenômeno da copresença (do público em relação aos atores, dos espectadores entre eles) constitui muito provavelmente uma das principais apostas da "sessão teatral" hoje: se ainda nos reunirmos no teatro, é principalmente para ver atores reais e podermos viver juntos, simultaneamente, a mesma experiência artística. De acordo com essa hipótese, a introdução de novas tecnologias em cena, resultante da necessidade de o teatro forjar um vínculo mais forte com o mundo atual, colocando em xeque nossos modos de viver, de comunicar, de pensar, entra em contradição com a expectativa de uma forma efêmera de refundação comunitária. Sem dúvida, essa é uma das razões pelas quais o processamento direto da imagem geralmente é privilegiado, pois retém a dimensão temporal (e às vezes até espacial, quando a ação filmada é visível sem ser intermediada câmera) da experiência compartilhada. Nesse regime amplamente dominante, a imagem do vídeo torna possível observar de maneira diferente uma ação cênica que é diretamente visível aos espectadores. Assim, pode servir, paradoxalmente, para manter de certa maneira o sentimento de copresença entre a cena e a sala, se inscrevendo numa espiral de validação recíproca: a tela, recebendo o traço luminoso da ação cênica, empresta o efeito de autoridade e verdade que emana de qualquer imagem gravada, enquanto o palco testemunha a conformidade entre o que a tela mostra e o que é realizado em sua base.

\section{A tela como uma cena rival}

Muito diferente é o caso das realizações cênicas que, como as evocadas anteriormente por Castorf, Pollesch ou pela companhia Motus, opõem-se com uma radicalidade muito maior aos protocolos da dupla presença: o do palco e o 
da sala, devido à ausência duradoura de atores no palco; a dos espectadores entre si, pela transformação parcial de uma plateia de teatro em plateia de cinema, ou seja, em um grupo de indivíduos separados uns dos outros pelo poder do fascínio pelas imagens. A espera por um instante de compartilhamento é, portanto, decepcionada, a representação teatral se recusando a constituir, diante da performance de intérpretes de carne e osso, a reunião de uma comunidade de sentidos e emoções.

Outras produções - de Denis Marleau e Zaven Paré, por exemplo21- levam essa recusa ainda mais longe, até a completa exclusão dos intérpretes vivos no palco, mostrando apenas máscaras nas quais são projetados os traços dos atores. Ao contrário desse "teatro de apagamento"22 integral, no entanto, as três produções que discutiremos aqui têm a característica comum de vincular a presença à ausência: os atores participam fisicamente da representação, mas a ação cênica, ocultando-os de nossa visão ou fornecendo obstáculos a ela, nos proíbe o acesso direto as suas performances. A tensão é, portanto, mais forte pelo fato de que o objeto do desejo está lá, que o conhecemos, mas que o prazer nos é negado.

\footnotetext{
${ }^{21}$ Ver, por exemplo, o dossiê duplo Modernité de Maeterlinck - Denis Marleau publicado em Alternatives théâtrales, $\mathrm{n}^{\circ}$ 73-74, Bruxelas, julho de 2002, e Le Théâtre des oreilles de Valère Novarina em Alternatives théâtrales, $n^{\circ}$ 72. Bruxelas, abril de 2002 (p. 8-23).

22 Zaven Paré, Sur le théâtre des oreilles - Sur le théâtre de l'effacement, in: Alternatives théâtrales, $n^{\circ} 72, \mathrm{p}$. 17-20.
} 
interpretadas em tempo real nos bastidores, na forma de um estúdio de televisão ou "bastidores eletrônicos" (para usar essa expressão de Giorgio Barberio Corsetti ${ }^{24}$ ), onde são reconstituídos a Judeia de Pôncio Pilatos e os imóveis de Moscou. A clínica psiquiátrica do Dr. Stravinski, também visível apenas na tela, é representada por uma célula e uma cabine de ducha formando uma câmara entre o bangalô de vidro e o estúdio de televisão. Quanto às cenas que acontecem na casa do Mestre ou na de Margarita, elas são exibidas em uma pequena sala construída acima do bangalô e ao lado da tela do lado cour ${ }^{25}$ os atores podem ser percebidos simultaneamente na moldura da janela desta sala, como se o público os estivesse observando de uma rua e visto de perto na tela, graças ao cinegrafista que os filma no interior da sala. O sentimento de frustração que surge da consciência de que as ações visíveis na tela ocorrem ao vivo, mas em um campo fora da visão, é fortalecido ainda mais pelo fato de que os atores, quando fisicamente presentes no palco, quase sempre permanecem separados dos espectadores pela parede transparente que forma a frente do bangalô, recuados no cenário - um dispositivo que o cenógrafo Bert Neumann já realizou para outra encenação de Castorf: Dämonen, de Dostoievski, em 2000. Portanto, é apenas através do duplo obstáculo da distância e de uma janela de acrílico que deslocamentos, imitações e gestos geralmente chegam até nós, como se estivessem parcialmente desencarnados, quando não aparecem apenas na tela. Evidentemente, essa escolha cenográfica incide sobre a percepção: a gravação do espetáculo mantida pela Volksbühne permite ouvir a interpelação, seguida de aplausos, de uma espectadora pedindo para os atores, que dialogam por trás da parede transparente, falarem mais alto.

Em Pablo in der Plusfiliale, de René Pollesch, as partes respectivas da presença real e da presença na tela são exatamente o oposto das apresentadas em Der Meister und Margarita: para um espetáculo de uma hora e meia, as aparições físicas dos atores somam pouco mais de vinte minutos ${ }^{26}$, enquanto a

\footnotetext{
${ }^{24}$ Ver Didier Plassard, Dioptrique des corps dans l'espace électronique: sur quelques mises en scène de Giorgio Barberio Corsetti, in : Béatrice Picon-Vallin (dir.), 1998, p. 149-170.

${ }^{25}$ Em francês, o lado cour refere-se à direita do palco, visto pela plateia. O lado esquerdo do palco, também visto pela plateia, chama-se jardin. (N.T.)

${ }^{26}$ Cálculo realizado a partir da gravação em vídeo do programa, Pablo in der Plusfiliale, Volksbühne Films,
} 
tela de vídeo com vista para a cena do Rollende-Road-Schau ${ }^{27}$ da Volksbühne em Berlim nunca se apaga. Além disso, ainda mais fortemente do que na encenação de Frank Castorf, os intérpretes evoluindo no palco ou entre os espectadores rivalizam com aqueles que, muitas vezes em close, continuam ocupando a imagem. A maior parte da ação cênica, filmada ao vivo, fica dissimulada aos olhos do público por um grande contêiner vermelho que, disposto lateralmente no lado cour, atua tanto como camarim quanto como um "bastidor eletrônico", enquanto uma plataforma lateral, do lado jardin, destina-se ao gerenciamento técnico. Alguns raros e minúsculos momentos de cena dentro do contêiner podem ser vistos através de uma abertura feita como uma janela sobre sua fachada, mas parcialmente ocultada por uma cortina de tiras cintilantes e a inscrição "BILLIG" ('barato'). Máquina para produzir a frustração do público do teatro, esse dispositivo cênico parece ter apenas a função de atestar a presença dos atores dentro do contêiner, enquanto os remove da exibição ao vivo durante três quartos do espetáculo.

Twin rooms, por sua vez, repousa sobre um princípio totalmente diferente. Nesta realização da companhia Motus, inspirada livremente no romance White Noise (Ruído branco) de Don DeLillo e em filmes de Abel Ferrara, Gus Van Sant e Wong Kar-wai, o público se depara com um duplo espaço cênico encimado, de modo geminado, por uma tela dupla de projeção de vídeo: enquanto a decoração construída no palco representa, separada por uma divisória perfurada por uma porta, o quarto e o pequeno banheiro de um motel americano, as duas telas colocadas logo acima têm exatamente a mesma forma e dimensões da estrutura das duas salas. Com exceção de alguns breves blackouts na tela ou momentos de escuridão no palco, essas quatro janelas abertas para a ação mobilizam alternadamente o olhar do espectador, sem que este último possa perceber tudo o que é realizado diante de seus olhos: tomando repentinamente consciência de uma mudança que ocorreu em um ou outro dos espaços concorrentes, ele é

${ }^{27}$ Concebido pelo cenógrafo Bert Neumann como um "contêiner teatral móvel", o Rollende-Road-Schau da Volksbühne é um palco sob uma cobertura aberta que permite a transmissão de shows, shows, filmes e várias animações, principalmente em áreas periféricas que "resistem ao teatro". Veja Hannah Hurtzig, RRS Rollende-Road-Schau de Rosa-Luxemburg-Platz, Das Mobile Container-Theater der Volksbühne, Alexander Verlag, Berlin, 2002. 
constantemente levado a mudar o foco de sua atenção.

A descontinuidade e o sentimento de confusão que resultam desses múltiplos rearranjos oculares são agravados pelos jogos de repetição, variação, prolongamento visual ou de contraponto expressivo que produzem alternância, nas telas, de imagens filmadas ao vivo de diferentes câmeras fixas ou móveis, bem como a introdução de algumas sequências gravadas. Finalmente, dois técnicos, um segurando uma câmera e o outro um microfone na ponta de uma vara, costumam intervir entre os atores presentes no palco e entre o público, de modo que toda a percepção do jogo se encontra contrariada: este, mais frequentemente direcionado às câmeras do que ao público, tende a se aproximar dos códigos cinematográficos, dando aos espectadores a sensação de assistir não a uma peça teatral, mas a gravação de um filme. A própria construção do espaço do palco, repleta de móveis e fechada por paredes paralelas que dificultam a percepção do fundo da cena, reforça esta impressão de um palco destinado a ser filmado mais do que observado por uma plateia de teatro.

\section{O teatro enfraquecido}

Dentro de cada uma dessas três produções, a ação cênica se encontra, portanto, deslocada, ocultada ou dificultada pelo (mas também pelo benefício do) dispositivo fílmico, enquanto a imagem de vídeo, de grandes dimensões, poderosamente iluminada e pendendo a cena ao modo das telas gigantes usadas em shows de rock ou em certas reuniões políticas, se impõe brutalmente aos olhares. O teatro aqui deixa de se definir como o lugar da manifestação dos corpos vivos, ou mesmo o da reunião ou a hibridação entre a realidade física e a imagem projetada, para se tornar o de um combate desigual entre, por um lado, uma cena material enfraquecida ou marginalizada e, por outro, uma "cena" eletrônica, usando todo o seu poder de espanto.

Esse enfraquecimento dos recursos próprios do teatro não resulta apenas do dispositivo cênico ou do rebaixamento de grande parte da ação fora da esfera de visibilidade imediata. A rivalidade entre a cena e a imagem é de fato acompanhada, 
em Castorf e Pollesch, por um desequilíbrio acentuado entre suas respectivas funções dramatúrgicas. Em Der Meister und Margarita, a tela é o instrumento privilegiado da gag visual (a marcha oscilante de um gato de desenho animado para acompanhar Woland cantando Sympathy for the deviR, a cabeça de Berlioz cortada pelas rodas do bonde, as desventuras do diretor do Teatro de Variedades transportado para longe de Moscou), da gag verbal (os comerciais de uma sala de cinema pornô), ao mesmo tempo que ela acolhe um grande número de momentos-chave do romance de Bulgakov (o confronto de Pôncio Pilatos e Yeshua, as cenas da clínica psiquiátrica, o encontro de Margarita e Azarello, o voo para a noite de sabá, etc.), tratados de maneira dramática ou cômica. O bangalô de vidro, por outro lado, possui uma lanchonete medíocre decorada com a inscrição neon "/ want to believe" ("quero acreditar") e um salão com bilhar. Nesse espaço inteiramente dedicado à espera, os personagens conversam, fumam, bebem, movem as cadeiras, arrumam um pouco o espaço, descansam no sofá, fazem piqueniques etc. Seu papel pode até parecer ainda mais irrisório, graças a algumas breves entradas em cena: vemos, por exemplo, um dos residentes da clínica sair da tela, empurrar a porta da câmara que o leva ao palco, diretamente à vista do público, pegar uma bebida na geladeira da lanchonete e depois retornar ao seu quarto na tela, reduzindo assim o espaço teatral à função de uma simples reserva de acessórios no campo externo da imagem.

${ }^{28}$ Como Castorf lembra, essa música dos Rolling Stones é diretamente inspirada na leitura de Mick Jagger sobre o romance de Bulgakov. 
Figura 2 - Pablo in der Plusfiliale 29

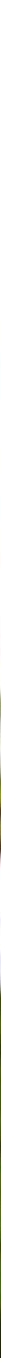

Em contraste com uma ação cênica tão frágil ou tão lenta, a tela assume um jogo muito mais intenso: enquadramentos em planos fechados, olhando para a câmera muitas vezes ou até mesmo falando com ela, os atores superam em expressividade os usuários amadores de uma webcam. Então, quando Margarita perdeu a pista do Mestre, vemos a atriz Katrin Angerer, miando de raiva e desespero, vagando de quatro em prédios em miniatura, olhando alternadamente para o objetivo e as janelas iluminadas; então, quando aprende do demônio

${ }^{29}$ Fonte: https://www.annamonteverdi.it/digital/lecran-contre-la-scene-tout-contre-motus-rene-polleschfrank-castorf-par-didier-plassard/. Acesso em: 13 jan. 2021. 
Azarello que poderá salvar seu amante se concordar em ir a uma noite de sabá, a jovem multiplicando as caretas, a gagueira cômica e as demonstrações de espanto diante de uma câmera que estica seus traços à medida que ela se aproxima, tomando os espectadores como testemunhas diante da estranheza do personagem e de sua proposição.

Em Pablo in der Plusfiliale, as raras aparições materiais dos atores são acompanhadas por repentinas descargas de energia (gritos, explosões de raiva) ou momentos lúdicos (anúncios de vendas e venda ao público, jogos, breves passagens da cena) formando contraste com a ação que ocorre dentro do contêiner, quase inteiramente composta de falas para a tela. Para essas últimas, o olhar para a câmera, microfone mantido à mão na frente da boca, é a regra: os intérpretes, emoldurados em close, dirigem-se de maneira posada, cúmplice ou relaxada aos espectadores, como se estivessem falando na televisão. Violentamente iluminados, desproporcionalmente ampliados pela projeção, acompanhados de música de fundo sincopada em tons latino-americanos, seus rostos são visualmente impostos acima do palco. E se as proposições, como frequentemente com Pollesch, são tantos textos-manifestos inspirados em estudos sociológicos, pontuados com palavrões e que parecem distribuídos aleatoriamente entre os intérpretes, eles afirmam posições políticas ou socioeconômicas que fazem da tela uma tribuna ${ }^{30}$. A entrada em cena, portanto, aparece apenas como um parêntese na série desses discursos, um breve momento de saída pelas frustrações as quais testemunham - a menos que, como no número do karaokê no qual termina a representação, não sela permanentemente a submissão da performance teatral à imagem midiática.

\footnotetext{
30 "Porque a peça [...] foi estreada no Festival do Ruhr, co-financiada pelos sindicatos, Pollesch reflete o mais perversamente possível sobre a desordem com a qual os sindicatos reagem a um capitalismo cada vez mais severo. e a ruptura dos sistemas de proteção social. Por um lado, [ele] expressa sua solidariedade com os movimentos de protesto contra o neoliberalismo. Mas, ao mesmo tempo, Pollesch, profissional marginal, mostra claramente a fronteira que o separa das atuais 'classes médias' da DGB (Deutscher Gewerkschaftsbund): quando jamais pertencemos ao centro social, tomamos conhecimento com um leve prazer inteligente forma como as garantias dos cidadãos são quebradas. E nos remetemos a economia paralela, as redes sociais e as coisas usadas pelos marginalizados para garantir sua sobrevivência. (Peter Laudenbach, em Der Tagesspiegel online, 28 de maio de 2004, citado no site do Goethe-Institut: http://www.goethe.de/kue/the/nds/nds/aut/pol/stu/ frindex.htm \# plusfiliale).
} 


\section{A presença recomposta}

Eu propus anteriormente a hipótese segundo a qual o sentimento de copresença entre o palco e a sala pode experimentar uma forma de reelaboração - ou mesmo, em alguns casos, reforçar - pela intromissão de telas, a transmissão ao vivo da imagem chegando a oferecer outro ponto de vista sobre uma ação teatral já visível dos espectadores, em um sistema duplo de validação recíproca. No entanto, esse não é o caso de Der Meister und Margarita de Castorf: primeiro porque, como no espetáculo de René Pollesch, a tela geralmente não duplica a cena física, cada local desenvolve a sua própria série de ações mais ou menos autônomas; mas também porque, nos raros momentos em que isso acontece, a relação entre os dois pontos de vista se estabelece frequentemente de acordo com o modelo da trucagem na imagem e sua explicação no palco. Assim, o voo de Woland e sua trupe é realizado pelos atores deitados de costas e agitando as pernas na sala de estar do bangalô, seu reflexo em um espelho oblíquo colocado acima deles sendo filmado por uma câmera e depois projetado na tela.

Twin rooms, por sua vez, fazem largo uso do dispositivo de vídeo para dar aos espectadores outro ponto de vista sobre a ação cênica, mas dentro de uma economia muito particular, porque é a imagem que restitui sua plena visibilidade a um jogo teatral distante e dificilmente perceptível devido à desordem do palco. Graças a ela, não temos apenas acesso ao detalhe da expressão dos gestos dos atores; também descobrimos, por exemplo, que a saída de uma das protagonistas, Eva, é apenas um fingimento, e que essa permanece oculta perto da porta envidraçada da sala para espionar as conversas; depois que a mesma Eva, algum tempo depois, desliza entre duas camas sem que os outros personagens perceberem e que ali, deitada no chão, ela olha para uma série de clichês fotográficos. Câmeras e técnicos, portanto, constroem um espaço sob controle, uma "cena vigiada" ${ }^{11}$ onde nada e ninguém parece poder escapar dos olhares.

${ }^{31}$ Cf. Georges Banu, La scène surveillée, Actes Sud, Arles, 2006. 
Mas é também a imagem do vídeo que, por meio da montagem dos planos (ou pela justaposição sobre as duas telas contíguas, na forma de um efeito de tela dividida - split-screen), pode aproximar os corpos e conectar os olhares dos intérpretes distanciados entre si ou que parecem se ignorar no palco, mesmo que estejam conversando. Um procedimento usual no teatro, uma vez que permite ao público de se perceber como destinatário indireto da resposta, o distanciamento do "face-a-face" entre os interlocutores é assim corrigido pelo sistema de projeção. De maneira comparável, monólogos e confissões, ditos pelos atores à frente da objetiva, aparecem na tela para serem dirigidos aos espectadores. A verdadeira máquina de visão, no sentido desenvolvido por Paul Virilio ${ }^{32}$, o dispositivo formado pelas várias câmeras, o gerenciamento técnico e as telas, se contribui em primeiro lugar para deslocar a imagem cênica em quatro janelas concorrentes, permite, portanto, em certos casos reconstruir as situações enunciativas e restaurar à ação dramática sua coerência, sem que seja sempre possível decidir se foi desconstruído no palco para produzir um efeito de excesso de teatralização ou para recriar as condições de uma filmagem .

Às vezes, acolhendo, na forma de sequências pré-gravadas, as memórias ou devaneios dos protagonistas, as telas também servem para prender a atenção do público, em particular nas sequências que resgatam, por longos momentos, os planos fixos de câmeras de vigilância. Embora tenha sido capaz de verificar, desde o início do espetáculo, que a imagem eletrônica do banheiro coincide exatamente com o original sobre o palco, o espectador descobre repetidamente várias diferenças: sentado no vaso sanitário, o protagonista masculino, Jack, está completamente vestido na tela enquanto ele só usa calças na realidade. Um pouco depois, um poodle, que aparece apenas na imagem, entra no mesmo banheiro: sem que o público tenha percebido, a captura ao vivo da câmera de vigilância deu lugar a uma sequência pré-gravada por ele. Repetida em um looping, a entrada do cachorrinho assume o significado de um prolongamento imaginário - e irônica do diálogo: dois atores, no palco, repetem uma situação extraída do filme por Gus Van Sant, My own private Idaho, na qual podemos ouvir simultaneamente o áudio:

${ }^{32}$ Ver Paul Virilio, La machine de vision, Galilée, Paris, 1988. 
(VOZ DO MIKE): Se eu tivesse pais normais, uma boa educação, eu poderia ter me tornado um cara bastante equilibrado, eu acho.

(VOZ DE SCOTT): Depende do que você chama de normal.

(VOZ DO MIKE): É verdade, sim. Enfim, quero dizer pessoas normais, do tipo papai, mamãe, com um cachorro, esse tipo de besteira ... Normal ... normal. Não, eu não tinha cachorro. ${ }^{33}$

Com esses pequenos deslocamentos, a imagem do vídeo comenta e, até certo ponto, expande os significados da ação cênica; mas, ao mesmo tempo, o jogo das diferenças, focalizando a atenção de modo durável, desvia os espectadores da interpretação dos atores e parasita a comunicação teatral. O efeito de distração resultante tende, portanto, a se aproximar dos métodos mais fortes usados por Frank Castorf em sua encenação de Der Meister und Margarita: por exemplo, quando, nos primeiros momentos da representação, a tela faz desfilar como em um outdoor luminoso os slogans burlescos de publicidade de um cinema pornô ("Você não quer ficar bravo com sua MULHER? OK! OK! OK! Fique quieto em casa e assista ARD ou ZDF ${ }^{34}$ - MAS - MAS - MAS PENSE BEM, conosco você também está sentado na PRIMEIRA FILA"), enquanto os atores que interpretam os dois escritores Berlioz e Biezdomny começaram a trocar seus pontos de vista sobre a verdadeira personalidade de Jesus no interior da lanchonete.

No que diz respeito a Twin rooms, no entanto, o principal obstáculo ao estabelecimento de uma relação direta entre atores e espectadores está, como já mencionei, na natureza intrusiva do equipamento técnico. Além de duas câmeras de vigilância colocadas no banheiro, podemos notar a presença de dois ou três técnicos (dependendo das representações), munidos com câmeras em tripés e posicionados no meio da plateia, que filmam a ação cênica a partir de ângulos de visão idênticos aos dos espectadores, mas com efeitos de zoom ou enquadramento modificando a escala e orientando a visão. Acima de tudo, um

${ }^{33}$ Gus Van Sant, My own private Idaho, longa-metragem, New Line Cinema, Estados Unidos, 1991. Versão dublada em francês deste filme que foi usada durante as apresentações de Twin rooms. No palco, no entanto, os atores repetiram essas réplicas em italiano, dando o mesmo texto para ser ouvido duas vezes com algumas leves transformações.

${ }^{34}$ Canais de televisão alemães. 
operador de som e um operador de câmera, evoluindo em primeiro plano e depois mais ao interior da cenografia, impõem-se visualmente na proximidade imediata dos atores, quando suas silhuetas simplesmente não se destacam diante deles; depois de cerca de vinte minutos (cerca de um quarto da representação), esses dois homens, por seu comportamentos cada vez mais estranho e invasivo começam a se afirmar como personagens autônomos, à margem da ação principal. Nós os vemos se filmarem a si mesmos, falando para se designarem como Vladimir e Damir, posando na frente das câmeras de vigilância no banheiro, escrevendo sobre o espelho, conversando entre si (para reproduzir, por exemplo, o trecho de My own private Idaho, citado anteriormente), mas também para comentar com uma mímica humorística ou imitar as trocas entre os dois protagonista, os amantes Jack e Cate que vivem o fim de seu relacionamento romântico. Pontuado com trechos da trilha sonora e situações emprestadas de Snack eyes (Dangerous game) de Abel Ferrara, que toma como argumento a realização de um filme sobre a separação de um casal, a ação de Twin rooms multiplica os paralelismos e as interferências entre ficção teatral, ficção cinematográfica, filmagem de um filme e preparação de um espetáculo, chegando ao ponto de interromper os atores em suas atuações para que escutem os conselhos em voz off, de um dos dois diretores da Companhia Motus, Enrico Casagrande ${ }^{35}$.

No entanto, não é apenas o pleno gozo de uma ação dramática, realizada por atores no palco, que é recusada nessas três produções pelo dispositivo de captura e projeção de vídeo: a imagem, ela também, conhece parasitas frequentes devido às aparições, no começo do quadro, do bastão de um gravador de som, de um microfone, até de outra câmera e do operador de câmera que o manipula. Mesmo a presença na tela dos intérpretes e o desenrolar da história filmada são, assim, frustrados pelas aproximações voluntárias do dispositivo técnico; a mídia deixa de funcionar como uma simples mediação para agir de maneira embaraçosa ou bagunçada.

As relações interpessoais dentro da esfera mimética, por exemplo, são

\footnotetext{
${ }^{35}$ A segunda é Daniela Nicolò.
} 
frequentemente desconstruídas pela presença da câmera e pelo poder de atração que ela parece exercer sobre os atores, de acordo com um regime que se relaciona ao uso da televisão, não da ficção cinematográfica. Esse é particularmente o caso de Pablo in der Plusfiliale: por si só, o uso sistemático do microfone de mão significa que o verdadeiro destinatário da resposta não é de forma alguma outro "personagem" (tanto quanto ainda possamos usar esse termo na análise dos espetáculos de René Pollesch), nem mesmo simplesmente um parceiro de cena, mas, como em um programa de televisão, o público na frente da tela. Os closeups nos rostos voltados para a lente e a sucessão de discursos destacados confirmam, portanto, o que a simples visibilidade do dispositivo de gravação de som anuncia: a recusa em constituir qualquer aparência de diálogo tanto na imagem quanto na cena. Essa justaposição de discursos solipsistas parece ainda mais surpreendente, pois os intérpretes multiplicam gestos de ternura ou cumplicidade entre si. O acolhimento familiar dos corpos, frequentemente filmados em repouso (sentados ou deitados) dentro do container, contrasta com um dispositivo enunciativo exclusivamente orientado para o espectador.

Como já aludi, várias sequências filmadas do Der Meister und Margarita também veem os intérpretes se afastando de seus parceiros de cena para olhar insistentemente para a câmera: testemunhar, interrogação muda, expressão de inquietude, de diversão ou de vergonha. É isso o que Marguerite faz em diversas ocasiões diante das estranhas propostas de Azarello ou Woland, o diretor do Théâtre des Variétés, Stepan Likhodieiev, em frente ao contrato supostamente assinado com sua mão que o mesmo Woland lhe apresenta, ou Biezdomny em seu celular, explicando ao diretor da clínica psiquiátrica curiosamente estendido ao lado dele, que ele conversou com um homem que viveu durante o tempo de Pôncio Pilatos, depois o ouviu dizer que ele pode deixar a clínica sempre que quiser. Em cada uma dessas situações, o questionamento do espectador pelo olhar da câmera cria uma forma de desvinculação da relação dialogada (os outros intérpretes presentes na imagem continuam se dirigindo ao seu parceiro como se nada tivesse acontecido), ao mesmo tempo em que coloca em perspectiva a situação de dupla enunciação própria da comunicação teatral. É, portanto, em certos aspectos, a recomposição de um efeito de copresença (e talvez, desse 
modo, uma re-teatralização) que ocorre dentro do dispositivo de vídeo, endereçao ao público através da imagem vindo renovar uma relação que a interposição da mídia eletrônica também está trabalhando para desfazer.

\section{O vivo como desordem}

Também podemos observar, na encenação de Castorf e no espetáculo da companhia Motus, vários momentos de brincadeira com as câmeras de vigilância: pelas poses afetadas que eles assumem na frente delas ou pelos olhares que eles the lançam, os personagens enfatizam que estão cientes de serem filmados, ou mesmo tentam estabelecer uma comunicação com aqueles que eles imaginam estarem os observando em suas telas de controle. Esses momentos lúdicos, que também contribuem, pelo menos indiretamente, para restabelecer o endereçamento ao público, também participam de um regime particular da relação às imagens, que merece ser examinado com mais cuidado. Pois se a imagem do vídeo é onipresente nessas três produções, se sua integração dentro da representação teatral desloca, ameaça, mas sem dúvida também recompõe os modos de operação desta, as formas que ela adotada estão longe de serem indiferentes.

É impressionante notar, em primeiro lugar, que um espetáculo tão nutrido por memórias cinematográficas quanto Twin rooms evoca, na tela, nada além de imagens emolduradas aproximadamente: seja que os atores entram e saem indiferentemente do campo das câmeras de vigilância; ou que as imagens, filmadas com uma câmera mantida no braço, apresentem a trepidação e as incertezas específicas desse tipo de filmagem; seja ainda que, mesmo com câmeras num tripé, os cinegrafistas acompanham os movimentos no palco com certa inépcia, muitas vezes sendo surpreendidos por uma saída do quadro ou por um gesto repentino que atravessa o primeiro plano. De um modo mais geral, os efeitos de zoom e os movimentos da câmera são realizados sem fluidez, com breves movimentos bruscos, tremidos, frequentes reenquadramentos e reajustes que, se conseguem recordar certos planos movimentados os quais Abel Ferrara 
encontrou inspiração em John Cassavetes, também destacam a mediação operada pela imagem eletrônica, revelando a presença de operadores ocupados em coletar vestígios da ação cênica. Sejam eles decorrentes do contraste entre a fixidez das câmeras de vigilância e a mobilidade dos corpos que se inscrevem em seu campo, ou ainda das aparentes dificuldades experimentadas pelo operador de câmera em seguir os intérpretes em seus deslocamentos, as incertas adições da presença cênica e da presença da tela proíbem que esquecemos a existência da máquina de visão ou o controle que ela exerce sobre as atividades do palco.

As escolhas estéticas que presidem o processamento da maioria das imagens de Der Meister und Margarita ${ }^{36}$, na realização da Volksbühne, são ainda mais desconcertantes. Frequentemente portadas, as câmeras aqui ainda aproximam os atores, permanecem em detalhes insignificantes, multiplicam perspectivas distorcidas e acidentes de ponto de vista (movimentos involuntários, dificuldades de foco, passagens inesperadas no campo etc.). Durante o encontro de Yeshua e Pôncio Pilatos, em particular, pode-se ver claramente, nos bastidores, a borda da tela da decoração representando uma paisagem da Judeia; e ainda a precipitação dos criados para encher a banheira do procurador romano sacode o operador de câmera e sua câmera cuja lente, durante o resto da sequência, preservará as gotas de água projetadas pelos salpicos do banho.

Mas, em outros momentos da apresentação, a tela também abriga várias sequências, sejam simplesmente tiradas de câmeras de vigilância (cinco minutos de plano fixo nos trilhos, aguardando o bonde que cortará a cabeça do escritor Berlioz), ou sejam caindo numa forma de prática amadora; por exemplo, imagens de Moscou que poderiam ter sido filmadas por qualquer turista que passasse pelas ruas da cidade ou cenas filmadas na pequena sala do Mestre e Margarita, comparáveis aos vídeos visíveis no youtube ou nos blogs de Internet: ausência duradoura de edição, enquadramento trêmulo, desfocagem, troca de um caractere para outro para seguir a fala, etc. Até os efeitos especiais feitos com o vídeo digital, ao incorporar um elemento filmado ao vivo em um fundo pré-gravado, exibem a

36 Deve-se notar que um pequeno número de sequências é filmado de uma maneira mais acadêmica: o enquadramento é fixo e o controle ao vivo dos efeitos de edição de campo / contra campo, alternando as origens do ponto de vista. É o caso, por exemplo, do segundo interlúdio filmado mostrando Pôncio Pilatos, durante sua discussão com Caifás. 
falta de jeito de um clipe amador devido à diferença de temperatura das cores e à ausência de conexão entre os dois planos da imagem: assim, a cabeça de Berlioz rolando entre os trilhos do bonde, um ator de frac dançando no jogo de xadrez dos acompanhantes de Woland ou o diretor de teatro Stepan Likhodieiev se encontrando em um deserto que é apresentado a ele como a cidade de Scheveningen (e não a de Yalta, onde ele pensava que estava ...), depois fugindo um caçador preto armado com uma lança no coração da savana africana.

Essa estética da webcam e do vídeo amador contrasta fortemente com a presença de equipes técnicas e também com o poder dos meios de divulgação utilizados: três dimensões de tela muito grandes, luminosidade e definição da projeção, etc. Mesmo o espetáculo de René Pollesch, se ele tende mais a se aproximar do regime televisivo da imagem - em particular com o uso visível de microfones, que colocam os atores na posição clássica de jornalista ou apresentador -, resolutamente se desvia dele devido ao tratamento informal do enquadramento e da ausência de edição. De uma duração de quase quatro minutos, o primeiro plano projetado após o escuro inicial, por exemplo, atua como uma cena de exposição: microfone na mão, uma das atrizes (Christine Groß) apresenta vários objetos dispostos dentro do container, bem como seus cinco parceiros de cena e um cachorro, aparentemente dormindo, morando juntos neste lugar. Nós a vemos cada vez perguntando "Was ist denn das?' "('O que é isso?'), A câmera segurada no ombro procurará o objeto ou o ator assim designado, aproximar-se-á, girará para enquadrá-la na imagem, e finalmente retornará da mesma maneira para o rosto da jovem que espera estar novamente face à lente da câmera para reformular sua pergunta.

Ainda mais marcante do que na encenação de Frank Castorf, a câmera de Pablo in der Plusfiliale explora os lugares com um constrangimento deliberado, rastreando a fonte das vozes quando não é imediatamente perceptível na tela ou então passeando para descobrir as atividades - muitas vezes mínimas - dos diferentes ocupantes, surpreendê-los em seus momentos de intimidade, recolher suas palavras etc. A quase completa ausência de montagem leva a varreduras ópticas muito longas no espaço interior do container, a mergulhos bruscos, rotações, idas e vindas que acompanham cada movimento do operador de câmera 
e parecem seguir os movimentos espontâneos de seu olhar. Nesse campo infinitamente móvel, os intérpretes desaparecem e reaparecem simplesmente deslizando na imagem, sem que a sequência dessas aparências construa uma narrativa, no sentido cinematográfico do termo, ou que realmente envolva algo além de simples variações temáticas ou rítmicas a partir da situação inicial.

Se é uma característica comum às três produções que acabamos de mencionar, é bom, como podemos ver, associar em uma nova e altamente desestabilizadora combinação para o público teatral a hiper-presença das telas, a redução ou o confinamento fora do escopo da ação cênica e o processamento informal das imagens projetadas. Se, em uma primeira análise, podemos ficar tentados a estabelecer uma relação de homologia entre o lugar dado ao dispositivo de vídeo nesses espetáculos e o lugar que as telas ou monitores geralmente ocupam em nossas vidas (fazendo desse novo paradigma de relações entre a cena e as imagens o reflexo das mudanças que estão ocorrendo na sociedade), parece claro que Frank Castorf, René Pollesch, Enrico Casagrande e Daniela Nicolò se recusam a fazer "cenas" eletrônicas que convocam no palco os simples veículos das imagens produzidas pela indústria cinematográfica ou midiática, ou suas imitações, mesmo distantes. Trazendo seus modelos para práticas visuais menos elaboradas, os diretores enfraquecem significativamente o poder de fascínio das telas e, acima de tudo, tentam compensar pelo olhar da câmera, o excesso de jogo ou a presença perceptível do operador os "efeitos da ausência" do ator no palco: de certa forma, a introdução massiva do dispositivo de vídeo no palco teatral é acompanhada por seu próprio corretivo.

Mas a predileção pelos modelos da webcam, da câmera de vigilância ou do filme amador, com as aproximações visuais que induz, deve sem dúvida também ser interpretada sobre um outro plano. Quase totalmente livre da gramática cinematográfica, a imagem de vídeo projetada em cena sempre revela um corpo, em toda sua singularidade desordenada: seja traindo cada movimento de quem usa a câmera e do seu olhar que ela prolonga, seja enfatizando, em contraste com sua própria imobilidade, as hesitações e os acidentes comuns da vida. Imagem selvagem ou instabilidade no quadro, o humano aparece sempre como desordem e inadequação, ou seja, na tentativa de se distanciar dos hábitos visuais que 
encontraram o regime médio das imagens mídiáticas. Entre as várias maneiras pelas quais o teatro compõe um espaço de perspectiva crítica diante da industrialização da mídia e do entretenimento, o jogo duplo da frustração das expectativas e da descentralização das imagens pelas energias do vivo não é, sem dúvida, um dos menos eficazes.

\section{Referências}

ALBERT-BIROT, Pierre. À propos d'un théâtre nunique, SIC, $\mathrm{n}$ ○ 8-9-10, agostooutubro de 1916. (Reed.) Paris: Jean-Michel Place, 1980.

APPIA, Adolphe. Notes de mise en scène für Den Ring des Nibelungen (1891-1892). In: OEuvres complètes, vol. 1. Lausanne: L'Age d'homme, 1983.

BANU, Georges. La scène surveillée. Arles: Actes Sud, 2006.

FREUD, Sigmund. Au-delà du principe de plaisir. Paris: Payot, 1968.

GUÉNOUN, Denis. L'Exhibition des mots et autres idées du théâtre et de la philosophie. Belfort: Circé, 1998.

LE BRETON, David. Anthropologie du corps et modernité. Paris: PUF, 1990.

LEHMANN, Hans-Thies. Postdramatisches Theater. Frankfurt / Main: Verlag der Autoren, 1999.

MAURIN, Frédéric. Usages et usures de l'image - Spéculations sur Le Marchand de Venise vu par Peter Sellars. In: PICON-VALLIN, Béatrice (dir.). Les Écrans sur la scène. Lausanne: L'Age d' homme, 1998, p. 71-105.

PARÉ, Zaven. Sur le théâtre des oreilles - Sur le théâtre de l'effacement. In: Alternatives théâtrales, ${ }^{\circ}{ }^{\circ} 72$, p. 17-20.

PICON-VALLIN, Béatrice. Hybridation spatiale, registres de présence. In: PICONVALLIN, Béatrice (dir.). Les Écrans sur la scène. Lausanne: L'Age d' homme, 1998, p. 9-35.

PLASSARD, Didier. Théâtre et politique - L'écriture de la violence dans Fin de partie et En attendant Godot, Études théâtrales, $n^{\circ}$ 20, Centre d'Études Théâtrales, Louvain, março de 2001, p. 79.

PLASSARD, Didier. Dioptrique des corps dans l'espace électronique: sur quelques mises en scène de Giorgio Barberio Corsetti. In: PICON-VALLIN, Béatrice (dir.). Les 
Écrans sur la scène. Lausanne: L'Age d'homme, 1998, p. 149-170.

VIRILIO, Paul. La machine de vision. Paris: Galilée, 1988.

Recebido em: 21/01/2021

Aprovado em: 26/01/2021 